\title{
A specific gene expression signature for visceral organ metastasis in breast cancer
}

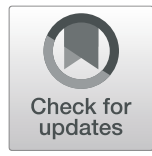

C. D. Savci-Heijink ${ }^{* *}$, H. Halfwerk' ${ }^{1}$ J. Koster ${ }^{2}$, H. M. Horlings ${ }^{3}$ and M. J. van de Vijver ${ }^{1 *}$

\begin{abstract}
Background: Visceral organ metastasis is associated with poor survival outcomes in terms of metastasis free- and overall survival in breast carcinomas. Identification of a gene expression profile in tumours that selects a subpopulation of patients that is more likely to develop visceral organ metastases will help elucidate mechanisms for the development of distant metastases and could be of clinical value. With this study we aimed to determine genomic predictors that would help to distinguish breast cancer patients with more likelihood to develop visceral metastasis.
\end{abstract}

Methods: Gene expression profiling data of 157 primary tumours from breast cancer patients who developed distant metastases were analyzed and differentially expressed genes between the group of tumours with visceral metastasis and the those without visceral metastases were identified. Published data were used to validate our findings. Multivariate logistic regression tests were applied to further investigate the association between the gene-expression-signature and clinical variables. Survival analyses were performed by the Kaplan-Meier method.

Results: Fourteen differentially expressed genes (WDR6, CDYL, ATP6VOA4, CHAD, IDUA, MYL5, PREP, RTN4IP1, BTG2, TPRG1, ABHD14A, KIF18A, S100PBP and BEND3) were identified between the group of tumours with and without visceral metastatic disease. Five of these genes (CDYL, ATP6VOA4, PREP, RTN4IP1 and KIF18A) were up-regulated and the other genes were downregulated. This gene expression signature was validated in the training and in the independent data set $(p 2.13 \mathrm{e}-08$ and $p 9$. $68 \mathrm{e}-06$, respectively). Multivariate analyses revealed that the 14-gene-expression-signature was associated with visceral metastatic disease ( $p 0.001,95 \%$ Cl 1.43-4.27), independent of other clinicopathologic features. This signature has been also found to be associated with survival status of the patients $(p<.001)$.

Conclusion: We have identified an unique gene expression signature which is specific to visceral metastasis. This 14-geneexpression-signature may play a role in identifying the subgroup of patients with potential to develop visceral metastasis.

Keywords: Organotropism, Pathology, Site-specific relapse, Microarray

\section{Background}

The implementation of breast cancer screening programmes and improved options for the treatment of patients with early breast cancer have contributed to the improved outcome in breast cancer [1]. However, once metastatic disease develops, breast cancer is still a deadly disease [2,3]. Predicting the likelihood of metastatic behaviour and organ-specific metastasis of the primary tumours could help to improve the modalities for the treatment of the primary tumour and of metastatic disease.

\footnotetext{
*Correspondence: c.d.savciheijink@amc.uva.nl; m.j.vandevijver@amc.uva.nl

'Amsterdam UMC, University of Amsterdam, Department of Pathology,

Meibergdreef 9, 1105 AZ Amsterdam, the Netherlands

Full list of author information is available at the end of the article
}

The relationship between primary tumour and their metastases has been an important area in cancer research since the "seed and soil' theory proposed by Stephen Paget [4]. Several studies have investigated the predictors for metastatic potential [5-7] of the primary tumours and site- specific distant organ metastasis [8-11] in breast cancer. Some of these studies using animal models and genomic profiling have identified gene expression signatures that were associated with organ specific metastasis. In particular, using an experimental system based on the in vivo selection of MDA-MB231- derived breast cancer cell lines with specific organotropism, Massague and co-workers have identified genes related to bone, lung and brain metastasis.

(c) The Author(s). 2019 Open Access This article is distributed under the terms of the Creative Commons Attribution 4.0 International License (http://creativecommons.org/licenses/by/4.0/), which permits unrestricted use, distribution, and 
They have suggested that whereas some genes may determine a breast cancer's overall classification and prognostic signature, some other superimposed tissue-specific metastatic gene expression profile(s) in a subset of tumour cells may affect the cancer's organ specific metastatic behaviour [12].

It has been demonstrated that metastases and primary breast cancers show similar gene expression profiles [13-15]. We previously reported gene expression profiling experiments performed on primary breast cancers to identify gene expression profiles for organ-specific metastasis. We have recently presented a novel 15-gene expression signature for bone specific metastasis in breast cancer [16]. This new gene expression signature was found to be associated with the likelihood of bone metastasis development in ER-positive and ER-negative tumours, in the training set as well as in an independent data set including 376 tumours with known clinical metastatic disease. We have shown that $80.5 \%$ of the patients with luminal subtype tumours developed bone metastasis as opposed to, respectively, 41.7 and $55.6 \%$ of the basal type and HER2-like tumours ( $p$ 0.001). We have also identified that $70.4 \%$ of luminal type tumours, $87.5 \%$ of basal type tumours and $77.8 \%$ of HER2-like tumours developed visceral organ metastasis (liver, lung and brain). Among basal type tumours $66.7 \%$ developed visceral metastasis as first metastasis site and $29.2 \%$ of these tumours had only visceral metastasis during the course of disease. Survival analyses revealed that patients who developed visceral metastasis had worse survival outcome, in terms of metastasis specific survival and overall survival and they frequently developed multiple metastasis during the course of the disease [17]. In this study we sought a gene expression profiling identifier to select the subgroup of tumours that are most likely to develop visceral organ metastasis.

Here we present a gene-expression signature which is found to be associated with development of visceral organ metastasis in breast carcinomas.

\section{Methods}

\section{Patients and tumour samples}

One hundred fifty-seven primary breast carcinomas from patients who all developed distant metastases were included in this study. This series of tumours has been described previously [17]. The national ethical guidelines of 'Code for Proper Secondary Use of Human Tissue' developed by Federation of Medical Societies (FMWV) in the Netherlands were followed for this study [18].

Clinical data with detailed information on metastatic behaviour, metastasis site and survival outcomes were collected from the clinical charts for 151 patients as previously published [17]. Briefly, metastasis site was carefully recorded and classified into ever versus never, first versus not first and only versus not only for each organ site. In addition, data on systemic treatment (chemotherapy, hormonal therapy and targeted therapy) used to treat primary and metastatic disease was also available for a subset of patients $(n=142$ and $n=122$, respectively). Tumours were evaluated and histological and immunohistochemical characteristics were assessed as previously published [17].

\section{Gene expression profiling and human breast tumour microarray data sets}

The methods for extraction, amplification and hybridization of RNA have been already explained [16]. Detailed information on these techniques is accessible via Illumina website (website (http://www.illumina.com). As described, the arrays were processed in the Central Microarray Facility of the Netherlands Cancer Institute. The data was normalized using robust spline normalization (rsn) and $\log 2$ transformed, followed by ComBat (http://www.bu.edu/jlab/wpassets/ComBat/Abstract.html) to adjust for batch effects. Next to this already published gene expression profiling data set of 157 primary breast tumours a combined data set (GSE2034, GSE12276, GSE2603 and the NKI295 (microarray-pubs.stanford.edu/wound_NKI/Clinical_Data_Supplem ent.xls) captured from public domain was used [19]. A subset of tumours $(n=376)$ with clinically proven metastatic disease was utilized for the analyses [19].

\section{Microarray data analysis}

All data were analyzed using the R2 (Microarray Analysis and Visualization Platform) web application, which is publicly available at http://r2.amc.nl. The tumours were also designated to have a "good prognosis" or a "poor prognosis" profile based on the 70-gene prognostic signature as described previously [16].

To validate already published gene expression signatures for lung metastasis $[10,11]$ and brain metastasis [8], the indicated genes were mapped to Illumina platform via Gene Symbol ID. As previously described [16], respectively a K-means method was used to cluster the patients in 2 groups and a t-test revealed the performance of these signatures in our dataset.

\section{Identification and validation of site-specific metastasis signature}

To identify a gene expression signature associated with organ specific metastasis, we used the one-way ANOVA function in R2. Only the genes with an expression level above background level were included in the analysis (total 16,051 genes). Samples were split into 2 groups; one group in which the patient developed a metastasis and another group in which a patient never developed a certain organ metastasis. The genes that showed a significant differential expression between these groups 
( $p$ value,0.0001) were included in the signature. The metastatic signature was subsequently validated in multiple datasets using the K-means and $\mathrm{t}$-test function in $\mathrm{R} 2$. To further investigate the link between this gene signature and clinical variables multivariate logistic regression tests were applied using SPSS Statistics for Windows (Release version 21.0;IBM Corp.2012, Armond, NY). Overall survival and metastasis free survival were analyzed by the Kaplan-Meier method in the training data set. Due to missing survival data in the publicly available files, additional survival analyses were not conducted in the independent dataset. All statistical tests were two sided and $p<0.05$ was considered to be statistically significant.

\section{Results}

From 157 primary invasive breast cancer from patients who developed distant metastases during follow-up, mRNA expression signatures were assessed using micro array analysis. The patient and tumour characteristics have been described previously [16].

Tumours were subdivided into molecular subtypes with the help of the PAM50 classifier [20]. The distribution of metastatic behaviour including site of metastasis, metastasis timeline and survival outcomes among the molecular subtypes have been published previously and are summarized in Table 1. Adjuvant systemic therapy was administered for $79.4,72.5,78.6$ and $87.5 \%$ of the patients with Luminal A, Luminal B, HER2-like and basal type tumours; respectively. Targeted therapy, by means of trastuzumab, was given to a subgroup of patients $(n=10)$ in the metastatic setting. The tumours were also subdivided into two groups as having "good prognosis" and "poor prognosis" based on their 70-gene expression profile.

\section{Validation of previously identified gene signature (s) for} lung and brain specific metastasis

We have investigated three previously published gene signatures for lung $[10,11]$ and brain metastasis $[8]$.
The gene expression signature (consisting of 54 genes) predicting lung metastases identified by Minn et al. [11] identified 55 primary tumours as having a "lung metastasis" gene expression signature. Out of the 55 tumours which positively tested for this signature, 17 (30.9\%) were found to have developed lung metastases. Of negatively tested primary tumours, $61(63.5 \%)$ had no lung metastasis $(p$ 0.594). When separated according to ER status, of 29 positively tested ER-positive tumours 6 (35.3\%) and of 26 positively tested ER-negative tumours 11 $(42.3 \%)$ developed metastatic disease to the lung ( $p 0.165$ and $p 0.368$, respectively). These results show that the 54 gene lung metastasis signature did not predict the development of lung metastases in our patient series. $70.8 \%$ of the basal type tumours, $44.4 \%$ of the HER2-like tumours and $27.7 \%$ of the luminal type tumours was positive for the lung metastasis associated gene expression signature.

The six-gene expression lung metastasis associated signature of Landemaine et al. [10] was present in 23 tumours. Nine (39.1\%) of these patients with positively tested tumours had lung metastasis, whereas of 128 patients with negatively tested tumours 85 (66.5\%) had no metastatic disease to lung ( $p$ 0.638).

$87.5 \%$ of the basal type tumours and $0.9 \%(n=1)$ of the luminal type tumours was positive for the signature. None of the HER2-like tumours were positive. The 17-gene expression signature of Bos et al. for brain specific metastasis was tested as positive in 56 tumours. Sixteen $(28.6 \%)$ of the patients with positively tested tumours developed brain metastases and 79 (83.2\%) of the patients with negatively tested tumours did not develop brain metastases ( $p$ 0.102). When the tumours which were positively tested for 17-gene signature [8] grouped according to ER-status, $11(44 \%, n=25)$ of ER-positive tumours and $12(38.7 \%, n=31)$ of ER-negative tumours had brain metastasis ( $p 0.795$ and $p$ 0.74, respectively). All basal type tumours, $33.3 \%$ of the HER2-like tumours and $24.1 \%$ of the luminal type tumours were positive for the brain metastasis associated gene expression signature.

Table 1 Distribution of metastatic behavior among molecular subtypes

\begin{tabular}{|c|c|c|c|c|c|c|c|c|c|}
\hline & & \multicolumn{2}{|c|}{ bone metastasis } & \multicolumn{2}{|c|}{ visceral metastasis } & \multicolumn{2}{|c|}{ metastasis timeline $^{a}$} & \multirow{2}{*}{$\begin{array}{l}\text { time to develop } \\
\text { metastasis }^{b}\end{array}$} & \multirow{2}{*}{$\begin{array}{l}\text { time to last } \\
\text { event }^{c}\end{array}$} \\
\hline & & yes & no & yes & no & early & late & & \\
\hline \multirow[t]{6}{*}{ Molecular subtype } & Luminal A & 54 & 11 & 41 & 24 & 48 & 18 & 45 & 37 \\
\hline & Luminal B & 33 & 10 & 35 & 8 & 33 & 10 & 41 & 40 \\
\hline & HER2 like & 10 & 8 & 14 & 4 & 15 & 3 & 35 & 21 \\
\hline & Basal type & 10 & 14 & 21 & 3 & 20 & 4 & 26 & 21 \\
\hline & Normal like & 1 & 0 & 1 & 0 & 1 & 0 & 10 & 1 \\
\hline & & \multicolumn{2}{|c|}{$p .001$} & \multicolumn{2}{|c|}{ p.090 } & \multicolumn{2}{|l|}{ p.749 } & p.052 & p.001 \\
\hline
\end{tabular}

\footnotetext{
${ }^{a}$ cut-off point, 5 years
}

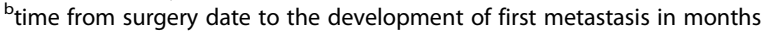

ctime from development of first metastasis to the last event (death/last follow-up) in months 


\section{Supervised classification of visceral organ metastasis related genes}

Subsequently, we have performed supervised classification comparing 112 tumours from patients who developed visceral metastases and 39 tumours from patients who did not develop visceral metastases. Using this approach,14 differentially expressed genes were identified. The 14 genes included in the visceral organ specific gene expression signature were WDR6, CDYL, ATP6V0A4, CHAD, IDUA, MYL5, PREP, RTN4IP1, BTG2, TPRG1, $A B H D 14 A, K I F 18 A, S 100 P B P$ and BEND3 (Table 2). Figure 1 illustrates the heat map with gene expression pattern of these 14 genes in all tumours. Six of these genes, CDYL, ATP6VOA4, PREP, RTN4IP1, BEND3 and $K I F 18 A$ were up-regulated and the other genes were down-regulated. None of these genes overlapped with the genes included in the already published gene expression signatures for lung and brain metastasis $[8,10,11]$. Mapping to the Gene Ontology and Kyoto Encyclopaedia of Genes and Genomes databases revealed that five of these genes (ABDHD14A, IDUA, ATP6V0A4, PREP and KIF18A) were involved in hydrolase activity.

This 14-gene expression signature for visceral metastasis was subsequently validated in the training and the independent datasets. This novel signature was found to be positive in 72 primary tumours of the patients with metastatic breast carcinoma. Out of the 14-gene expression signature positive 72 patients 68 (94\%) had visceral organ metastasis. Of 79 patients which were tested as negative for this signature, 35 (44.3\%) did not develop visceral metastatic disease ( $p 2.13 \mathrm{e}-08)$. Among the group of patients which had only visceral metastasis during the disease course $(n=18) 88.9 \%$ tested positive for the 14-gene expression signature ( $p 2.0 \mathrm{e}-04)$. Among the ones which had visceral organ metastasis as first site of metastasis $(n=68) 70.6 \%$ tested positive for the signature $(p 3.4 \mathrm{e}-07)$.

When tested separately in ER-positive and ER-negative tumour groups, $50 \%$ of the ER-positive tumours and $60.5 \%$ the ER-negative tumours were assessed as visceral metastasis signature positive. Out of $54 \mathrm{ER}+$ /signature + tumours $94.4 \%$ developed metastatic disease in a visceral organ; of $54 \mathrm{ER}+$ tumours/signature - tumours $53.7 \%$ did not develop visceral metastases $(p 3.2 \mathrm{e}-08)$. Of 24 ER-/signature+ tumours $91.7 \%$ had visceral organ metastasis and of 19 ER-/signature - tumours, 26.3\% did not have a visceral organ metastasis $(p 0.211)$.

Subsequently, the predictive value of 14-gene expression signature was investigated in an independent data set including 376 primary tumours of patients with metastatic breast carcinoma. Of 271 tumours assessed as visceral metastasis signature positive, 170 (62.7\%) developed visceral organ metastases. Out of 105 tumours which were tested as negative, 66 (62,9\%) had no evidence of metastatic disease to the visceral organs ( $p$ 9.68e-06). This 14-gene expression signature was also assessed separately in ER-positive and ER- negative tumour groups ( $n=373$, ER status was missing in 3 cases). The 14-gene expression signature was found to be positive in 160 of the 245 ER-positive cases. $50 \%$ of these ER + /signature+ tumours developed visceral organ metas-

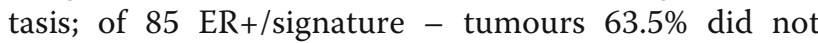
develop visceral metastases $(p 4.50 \mathrm{e}-02)$. There were 128 ER-negative tumours, 104 of which tested as positive for the visceral specific gene expression signature. $76 \%$ of these ER-/signature+ tumours developed visceral organ metastases; of 24 ER-negative tumours which were found to be negative for this

Table 2 The list of differentially expressed genes in visceral metastatic disease

\begin{tabular}{|c|c|c|c|c|c|c|}
\hline & Accession number & HUGO & Description & $R$-value & $p$-value & Level of expression $^{a}$ \\
\hline 1 & ILMN_1669484 & WDR6 & WD repeat domain 6 & $-0,319$ & $6,50 \mathrm{E}-05$ & $<$ \\
\hline 2 & ILMN_1678075 & CDYL & chromodomain protein, Y-like & 0,316 & $7,84 \mathrm{E}-05$ & $>$ \\
\hline 3 & ILMN_1678186 & ATP6V0A4 & ATPase, $\mathrm{H}+$ transporting, lysosomal V0 subunit a4 & 0,318 & $6,75 \mathrm{E}-05$ & $>$ \\
\hline 4 & ILMN_1700652 & CHAD & chondroadherin & $-0,319$ & $6,42 \mathrm{E}-05$ & $<$ \\
\hline 5 & ILMN_1703041 & IDUA & iduronidase, alpha-L- & $-0,325$ & 4,76E-05 & $<$ \\
\hline 6 & ILMN_1746948 & MYL5 & myosin, light chain 5, regulatory & $-0,313$ & 8,97E-05 & $<$ \\
\hline 7 & ILMN_1751887 & PREP & prolyl endopeptidase & 0,357 & $6,99 \mathrm{E}-06$ & $>$ \\
\hline 8 & ILMN_1758827 & RTN4IP1 & reticulon 4 interacting protein 1 & 0,314 & 8,84E-05 & $>$ \\
\hline 9 & ILMN_1770085 & BTG2 & BTG family, member 2 & $-0,389$ & $7,83 E-07$ & $<$ \\
\hline 10 & ILMN_1790350 & TPRG1 & tumor protein p63 regulated 1 & $-0,336$ & $2,41 \mathrm{E}-05$ & $<$ \\
\hline 11 & ILMN_1794213 & ABHD14A & abhydrolase domain containing 14A & $-0,321$ & $5,86 \mathrm{E}-05$ & $<$ \\
\hline 12 & ILMN_2132161 & KIF18A & kinesin family member $18 \mathrm{~A}$ & 0,341 & $1,81 \mathrm{E}-05$ & $>$ \\
\hline 13 & ILMN_2294274 & S100PBP & S100P binding protein & $-0,424$ & 5,87E-08 & $<$ \\
\hline 14 & ILMN_2375032 & BEND3 & BEN domain containing 3 & 0,316 & 7,91E-05 & $>$ \\
\hline
\end{tabular}

a $>$, up-regulated; <, down-regulated 


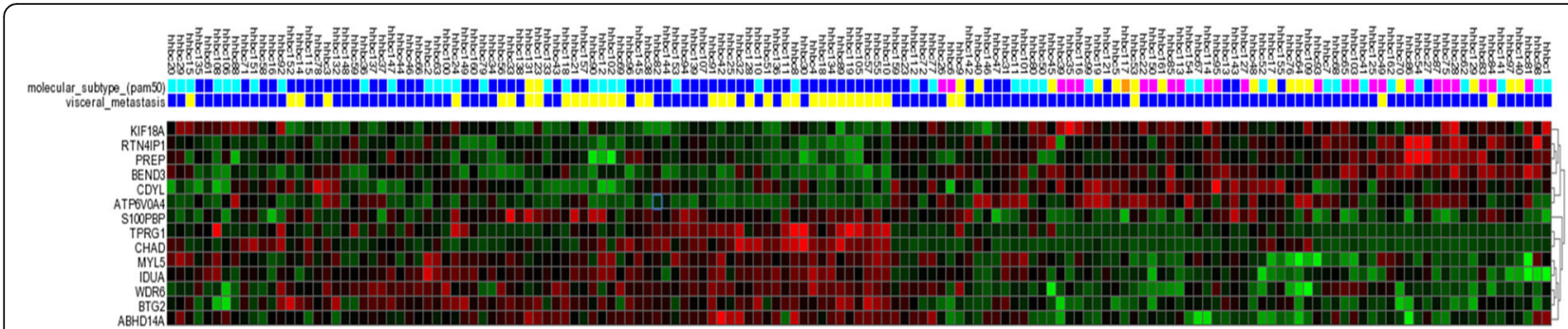

Fig. 1 The gene expression pattern of 14-gene expression signature for visceral metastasis in breast cancer. Heat map displays the gene expression profiling pattern of the 14 differentially expressed genes among 151 tumours. Primary tumours of the patients who developed visceral metastasis are illustrated in blue and the ones without visceral metastatic disease are in yellow. For each primary tumour the expression level of the specific gene is exhibited as red, if up-regulated and green, if down-regulated. Molecular subtypes of primary tumours are also demonstrated as; dark blue for luminal A, light blue for luminal B, yellow for HER2-like, pink for basal type and orange for normal-like tumours. *visceral metastasis: clinically evident visceral organ (liver, lung or brain) metastasis: yellow, absent; blue, present. ${ }^{* *}$ gene expression level: red, up-regulation; green, down-regulation. ${ }^{* *}$ molecular subtype: dark blue, luminal A; light blue, luminal B; yellow, HER2-like; pink, basal type; orange, normal-like

signature $33.3 \%$ had no evidence of visceral organ metastasis ( $p$ 4.37e-01).

Table 3 summarizes the performance of visceral metastasis specific gene expression signature in the data sets described.

Univariate analyses in the training dataset revealed that next to development of visceral organ metastasis (ever, as first site of metastasis and as the only metastasis) the 14-gene expression signature was also found to be significantly correlated to the histologic subtype of the tumour, ER status, PR status and molecular subtype of the primary tumour $(p 0.003, p<.001, p<.001, p<.001$ and $p<.001$, respectively). The other parameters that were associated with development of visceral organ metastases were tumour size $(p$ 0.002) tumour grade $(p$ 0.009) and tumour type ( $p$ 0.008). Multivariate analyses showed that along with tumour type the 14-gene expression signature was remained significantly correlated to visceral organ metastasis ( $p 0.001,95 \%$ CI 1.43-4.27).

Similarly, univariate analyses in the independent dataset showed that the 14-gene expression signature was significantly correlated with the development of metastatic disease to visceral organs $(p<.001)$. Molecular subtype of the tumour, ER status, PR status and lymph node status were the other parameters that were statistically related to visceral metastasis in this data set. Multivariate analysis showed that hormone receptor status (ER and HER2) remained significantly correlated to the development of visceral metastases ( $p 0.047,95 \%$ CI -3.36-0.003, ER status; $p 0.025,95 \% \mathrm{CI} 0.2-3.2)$ whereas the 14-gene expression signature was not retained as a significant predictor (p 0.49, 95\% CI -0.97-1.9).

Additional survival analyses in the training dataset exhibited that the 14-gene expression signature was associated with survival status of the patients, indicated by metastasis free survival and overall survival ( $p 0.001$ and $p<.001$, respectively).

\section{Discussion}

Development of visceral organ metastases in breast carcinoma is related to dismal prognosis with poor overall and metastasis free survival rates [17, 21]. The identification of genomic tumour characteristics associated with a higher likelihood of developing visceral organ metastasis

Table 3 Performance of the gene expression signature

\begin{tabular}{|c|c|c|c|c|c|c|c|c|}
\hline \multirow[t]{2}{*}{ Gene expression signature } & & \multirow[t]{2}{*}{ Signature } & \multicolumn{3}{|c|}{$\begin{array}{l}\text { Training data set } \\
\text { Visceral metastasis }\end{array}$} & \multicolumn{3}{|c|}{ Independent data set } \\
\hline & & & yes & no & $p$ & yes & no & p \\
\hline \multirow[t]{6}{*}{ 14-gene expression signature ${ }^{a}$} & All & present & 68 & 4 & $2.13 e-08$ & 170 & 101 & $9.68 e-06^{*}$ \\
\hline & & absent & 44 & 35 & & 39 & 66 & \\
\hline & ER-positive & present & 51 & 3 & $3.2 e-08$ & 80 & 80 & $4.50 e-02^{* *}$ \\
\hline & & absent & 25 & 29 & & 31 & 54 & \\
\hline & ER-negative & present & 22 & 2 & 0.211 & 79 & 25 & $4.37 e-01^{* * *}$ \\
\hline & & absent & 14 & 5 & & 16 & 8 & \\
\hline
\end{tabular}

Abbreviations: $E R$, estrogen receptor

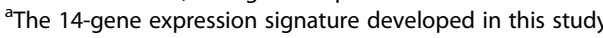

*sensitivity: $81.3 \%$, specificity: $39.5 \%$

**sensitivity: $72.1 \%$, specificity: $40.3 \%$

***sensitivity: $83.2 \%$, specificity: $24.2 \%$ 
will help understanding the mechanisms leading to the development of visceral metastases. In this study, we have compared the gene expression profiles of primary tumours of breast cancer patients who developed visceral organ metastasis to the ones without visceral metastasis using gene-expression microarrays. We have identified a unique group of genes which were differentially expressed in the group of tumours with clinical metastatic disease to the visceral organs. This association between 14- gene expression signature was significant not only with development of visceral organ metastasis (any time, as first site and as only site of metastasis) but also with both overall survival and metastasis free survival.

The identified gene expression signature included 14 genes, five (CDYL, ATP6VOA4, PREP, RTN41P1, BEND3 and Kif18A) of which were up-regulated in the group of primary tumours of the patients with visceral organ metastasis. Two of these genes (Kif18a and ATP6VOA4) have been already reported to be associated with human breast carcinogenesis [22-25]. Kif18a, kinesin family number 18a, which has function to produce force and movement along microtubules, was previously found to be deregulated in different cancers including breast cancer [25]. It has been shown that overexpression of Kif18a is associated with tumour grade, development of metastasis and poor survival. Functional analyses have also shown that ablation of this protein results in inhibition of proliferative capability of breast cancer cells with inactivation of phosphatidylinositol 3-kinase-Akt signalling pathway [24]. Zou et al. have shown that knockdown of kinesin gene family members strongly disrupted the proliferation and induced the apoptosis in both tamoxifensensitive and resistant breast cancer cells and they have suggested the potential role of developing novel inhibitors of the kinesins for effective treatment of human cancers including tamoxifen-resistant breast cancer [25]. ATP6VOA4, vacuolar ATPase, $\mathrm{H}+$ transporting, lysosomal V0 subunit a4, was another gene that found to be up-regulated in the group of tumours from patients with visceral metastatic disease. Previous studies have suggested an association between vacuolar ATPases (V-ATPase) and tumour invasion [26, 27]. Also, specific V-ATPase inhibitors, such as bafilomycin and concanamycin, have been shown to inhibit invasiveness of MDA-MB231 breast cancer cell lines [22, 23]. Subunit isoforms a3 and a4 are expressed at high levels in highly invasive breast cancer cell lines (MB231). It has been speculated that isoform a4 (ATP6VOA4) is involved in targeting V-ATPAse in cell membrane and this V-ATPase plays a role in invasive capability of these cells. This effect may be caused by locally acidifying the extracellular environment which may accelerate tumour invasion via creating an optimal acidic environment for proteases [28]. Further clinical studies investigating the effect of V-ATPase inhibitors on tumour invasiveness and metastasis will be of interest.

Nine out of 14 genes were downregulated in the subgroup of tumours with visceral organ metastasis. One of these downregulated genes is BTG2 (B- cell translocation gene-2), which has antiproliferative activity and has been reported to be altered in breast tumours $[7,29,30]$. It has also been shown that decrease of BTG2 expression in human breast cancer correlates with disease progression [31]. In order to explore the underlying mechanism, Takahashi and colleagues have further implemented experimental studies showing that knockdown of BTG2 expression led to increased cell motility. They have also demonstrated that BTG2 suppresses the activation of the HER2 pathway and suggested that HER pathway inhibitors, such as lapatinib, may play a role in controlling the progression of disease among breast cancers with decreased BTG2 expression. Moreover, the same group has demonstrated a modulator role of BTG2 on tamoxifen responsiveness in ER-positive/HER2-negative breast cancer and further validated BTG2 expression as a single predictor of survival following tamoxifen therapy [32]. Likewise, protein expression levels of BTG2 have also been found to be associated with 5-year overall survival in breast cancer patients. A prognostic model combining BTG2 expression, HER2 expression, patient age and Ki67 expression has been proposed with higher prediction accuracy than the currently used prognostic markers [33]. Consistent with the published data, we have shown that lower BTG2 expression was associated with shorter survival time ( $p$ 2.6e-04). Luminal type tumours had higher gene expression levels of BTG2 compared to HER2-like and basal type tumours $(p$ 1.6e-10) and our current study has revealed a strong correlation between BTG2 expression and visceral metastasis ( $p$ 2.13e-08).

\section{Conclusions}

With this study, we present a unique 14-gene expression signature for visceral metastasis in breast carcinomas. Further validation of this gene expression signature is warranted in order to test the reproducibility and the robustness of the correlations between the signature and metastatic behaviour.

\section{Additional file}

Additional file 1: Illumina microarray data generated in this study. (XLSX 41 kb)

\section{Abbreviations}

CT: Chemotherapy; ER: Estrogen receptor; HER2: Human epidermal growth factor receptor 2; HT: Hormonal therapy; MSS: Metastasis specific survival; OS: Overall survival; PR: Progesterone receptor; RECIST: Response evaluation criteria in solid tumours 


\section{Acknowledgements}

Not applicable.

\section{Funding}

This research was supported by the Center for Translational Molecular Medicine (BreastCARE). This funding has been utilized in the design of the study and the data collection.

\section{Availability of data and materials}

The microarray data generated in this study is included as Additional file 1.

\section{Disclaimer}

This work has been published during the review/revision process [34].

\section{Authors' contributions}

Conceived and designed the study: CDS-H, MJV. Contributed reagents/materials/analysis tools: $\mathrm{HH}$. Analysed the data: CDS-H, HH, JK, MJV. Drafted the paper: CDS-H and MJV. Read and approved the final manuscript: $\mathrm{CDSH}, \mathrm{HH}$ $\mathrm{JK}, \mathrm{HMH}$ and MJV.

\section{Ethics approval and consent to participate}

This study material was strictly handled after coding of the data according to national ethical guidelines of 'Code for Proper Secondary Use of Human Tissue' developed by Federation of Medical Societies (FMMM) in the Netherlands [18] The entire study protocol was approved by the Medical Ethical Committee of the Academic Medical Center. The need for obtaining informed consent was waived by this committee.

\section{Consent for publication}

Not applicable.

\section{Competing interests}

The authors declare that they have no competing interests.

\section{Publisher's Note}

Springer Nature remains neutral with regard to jurisdictional claims in published maps and institutional affiliations.

\section{Author details}

${ }^{1}$ Amsterdam UMC, University of Amsterdam, Department of Pathology, Meibergdreef 9, 1105 AZ Amsterdam, the Netherlands. ${ }^{2}$ Amsterdam UMC, University of Amsterdam, Department of Oncogenomics, Meibergdreef 9, 1105 AZ Amsterdam, the Netherlands. ${ }^{3}$ The Netherlands Cancer Institute, Department of Pathology, 1066 CX Amsterdam, the Netherlands.

\section{Received: 12 April 2018 Accepted: 31 March 2019}

\section{Published online: 08 April 2019}

\section{References}

1. Cummings MC, Simpson PT, Reid LE, Jayanthan J, Skerman J, Song S, McCart Reed AE, Kutasovic JR, Morey AL, Marquart L, et al. Metastatic progression of breast cancer: insights from 50 years of autopsies. $J$ Pathol. 2014:232(1):23-31.

2. Sant M, Allemani C, Berrino F, Coleman MP, Aareleid T, Chaplain G, Coebergh JW, Colonna M, Crosignani P, Danzon A, et al. Breast carcinoma survival in Europe and the United States. Cancer. 2004;100(4):715-22.

3. Thomssen C, Diel I, Gnant M, Goldmann-Posch U, Goschke C, Haidinger R, Janni W, Lin NU. Follow-up after breast cancer diagnosis. Breast Care (Basel). 2013;8(6):457-60.

4. Paget S. The distribution of secondary growths in cancer of the breast. 1889. Cancer Metastasis Rev. 1989, 8(2):98-101.

5. Nuyten DS, van de Vijver MJ. Gene expression signatures to predict the development of metastasis in breast cancer. Breast Dis. 2006;26:149-56.

6. Paik S, Shak S, Tang G, Kim C, Baker J, Cronin M, Baehner FL, Walker MG, Watson D, Park T, et al. A multigene assay to predict recurrence of tamoxifentreated, node-negative breast cancer. N Engl J Med. 2004;351(27):2817-26.

7. van de Vijver MJ, He YD, van't Veer LJ, Dai H, Hart AA, Voskuil DW, Schreiber GJ, Peterse JL, Roberts C, Marton MJ, et al. A gene-expression signature as a predictor of survival in breast cancer. NEnglJMed. 2002;347(25):1999-2009.
8. Bos PD, Zhang XH, Nadal C, Shu W, Gomis RR, Nguyen DX, Minn AJ, van de Vijver MJ, Gerald WL, Foekens JA, et al. Genes that mediate breast cancer metastasis to the brain. Nature. 2009;459(7249):1005-9.

9. Kang Y, He W, Tulley S, Gupta GP, Serganova I, Chen CR, Manova-Todorova K, Blasberg R, Gerald WL, Massague J. Breast cancer bone metastasis mediated by the Smad tumor suppressor pathway. Proc Natl Acad Sci U S A. 2005;102(39):13909-14.

10. Landemaine T, Jackson A, Bellahcene A, Rucci N, Sin S, Abad BM, Sierra A, Boudinet A, Guinebretiere JM, Ricevuto E, et al. A six-gene signature predicting breast cancer lung metastasis. Cancer Res. 2008;68(15):6092-9.

11. Minn AJ, Gupta GP, Padua D, Bos P, Nguyen DX, Nuyten D, Kreike B, Zhang $Y$, Wang $Y$, Ishwaran $H$, et al. Lung metastasis genes couple breast tumor size and metastatic spread. Proc Natl Acad Sci U S A. 2007;104(16):6740-5.

12. Gupta GP, Massague J. Cancer metastasis: building a framework. Cell. 2006; 127(4):679-95.

13. Ramaswamy S, Ross KN, Lander ES, Golub TR. A molecular signature of metastasis in primary solid tumors. Nat Genet. 2003;33(1):49-54.

14. van 't Veer LJ, Dai H, van de Vijver MJ, He YD, Hart AA, Mao M, Peterse HL, van der Kooy K, Marton MJ, Witteveen AT, et al. Gene expression profiling predicts clinical outcome of breast cancer. Nature. 2002;415(6871):530-6.

15. Weigelt B, Glas AM, Wessels LF, Witteveen AT, Peterse JL, van't Veer LJ. Gene expression profiles of primary breast tumors maintained in distant metastases. Proc Natl Acad Sci U S A. 2003;100(26):15901-5.

16. Savci-Heijink CD, Halfwerk $H$, Koster J, van de Vijver MJ. A novel gene expression signature for bone metastasis in breast carcinomas. Breast Cancer Res Treat. 2016;156(2):249-59.

17. Savci-Heijink CD, Halfwerk H, Hooijer GK, Horlings HM, Wesseling J, van de Vijver MJ. Retrospective analysis of metastatic behaviour of breast cancer subtypes. Breast Cancer Res Treat. 2015;150(3):547-57.

18. Vermeulen E, Geesink I, Schmidt MK, Steegers C, Verhue D, Brom FW, Aaronson NK, van Leeuwen FE. Secondary use of human tissue: consent and better information required. NedTijdschrGeneeskd. 2009;153:A948.

19. Harrell JC, Prat A, Parker JS, Fan C, He X, Carey L, Anders C, Ewend M, Perou CM. Genomic analysis identifies unique signatures predictive of brain, lung, and liver relapse. Breast Cancer ResTreat. 2012:132(2):523-35.

20. Parker JS, Mullins M, Cheang MC, Leung S, Voduc D, Vickery T, Davies S, Fauron C, He X, Hu Z, et al. Supervised risk predictor of breast cancer based on intrinsic subtypes. J Clin Oncol. 2009;27(8):1160-7.

21. Solomayer EF, Diel IJ, Meyberg GC, Gollan C, Bastert G. Metastatic breast cancer: clinical course, prognosis and therapy related to the first site of metastasis. Breast Cancer Res Treat. 2000:59(3):271-8.

22. Rojas JD, Sennoune SR, Maiti D, Bakunts K, Reuveni M, Sanka SC, Martinez GM, Seftor EA, Meininger CJ, Wu G, et al. Vacuolar-type H+-ATPases at the plasma membrane regulate $\mathrm{pH}$ and cell migration in microvascular endothelial cells. Am J Physiol Heart Circ Physiol. 2006:291(3):H1147-57.

23. Sennoune SR, Bakunts K, Martinez GM, Chua-Tuan JL, Kebir Y, Attaya MN, Martinez-Zaguilan R. Vacuolar H+-ATPase in human breast cancer cells with distinct metastatic potential: distribution and functional activity. Am J Physiol Cell Physiol. 2004;286(6):C1443-52.

24. Zhang C, Zhu C, Chen H, Li L, Guo L, Jiang W, Lu SH. Kif18A is involved in human breast carcinogenesis. Carcinogenesis. 2010;31(9):1676-84.

25. Zou JX, Duan Z, Wang J, Sokolov A, Xu J, Chen CZ, Li JJ, Chen HW. Kinesin family deregulation coordinated by bromodomain protein ANCCA and histone methyltransferase MLL for breast cancer cell growth, survival, and tamoxifen resistance. Mol Cancer Res. 2014;12(4):539-49.

26. Forgac M. Vacuolar ATPases: rotary proton pumps in physiology and pathophysiology. Nat Rev Mol Cell Biol. 2007;8(11):917-29.

27. Ohta $T$, Numata M, Yagishita H, Futagami F, Tsukioka $Y$, Kitagawa $H$ Kayahara M, Nagakawa T, Miyazaki I, Yamamoto M, et al. Expression of $16 \mathrm{kDa}$ proteolipid of vacuolar-type $\mathrm{H}(+)$-ATPase in human pancreatic cancer. Br J Cancer. 1996:73(12):1511-7.

28. Hinton A, Sennoune SR, Bond S, Fang M, Reuveni M, Sahagian GG, Jay D, Martinez-Zaguilan $R$, Forgac M. Function of a subunit isoforms of the $V$ ATPase in $\mathrm{pH}$ homeostasis and in vitro invasion of MDA-MB231 human breast cancer cells. J Biol Chem. 2009:284(24):16400-8.

29. Duriez C, Falette N, Audoynaud C, Moyret-Lalle C, Bensaad K, Courtois S, Wang Q, Soussi T, Puisieux A. The human BTG2/TIS21/PC3 gene: genomic structure, transcriptional regulation and evaluation as a candidate tumor suppressor gene. Gene. 2002;282(1-2):207-14.

30. Mollerstrom E, Delle U, Danielsson A, Parris T, Olsson B, Karlsson P, Helou K. High-resolution genomic profiling to predict 10-year overall survival in node-negative breast cancer. Cancer Genet Cytogenet. 2010;198(2):79-89. 
31. Takahashi F, Chiba N, Tajima K, Hayashida T, Shimada T, Takahashi M, Moriyama H, Brachtel E, Edelman EJ, Ramaswamy S, et al. Breast tumor progression induced by loss of BTG2 expression is inhibited by targeted therapy with the ErbB/HER inhibitor lapatinib. Oncogene. 2011;30(27): 3084-95.

32. Takahashi M, Hayashida T, Okazaki H, Miyao K, Jinno H, Kitagawa Y. Loss of B-cell translocation gene 2 expression in estrogen receptor-positive breast cancer predicts tamoxifen resistance. Cancer Sci. 2014;105(6):675-82.

33. Mollerstrom E, Kovacs A, Lovgren K, Nemes S, Delle U, Danielsson A, Parris T, Brennan DJ, Jirstrom K, Karlsson P, et al. Up-regulation of cell cycle arrest protein BTG2 correlates with increased overall survival in breast cancer, as detected by immunohistochemistry using tissue microarray. BMC Cancer. 2010;10:296.

34. Savci Heijink CD. Genomic characteristics of metastatic breast cancer. Amsterdam: University of Amsterdam; 2019.

Ready to submit your research? Choose BMC and benefit from:

- fast, convenient online submission

- thorough peer review by experienced researchers in your field

- rapid publication on acceptance

- support for research data, including large and complex data types

- gold Open Access which fosters wider collaboration and increased citations

- maximum visibility for your research: over $100 \mathrm{M}$ website views per year

At $\mathrm{BMC}$, research is always in progress.

Learn more biomedcentral.com/submissions 